\title{
Importance of Accompanying Information on Hearing Handicap
}

\author{
Ana Murta* \\ Bachelor of Audiology, Coimbra Health School, Master Student of Biomedical Sciences, University Beira Interior, Professor of Audiology at Speech \\ Therapy, School of Health at Setubal's Polytechnic, Portugal
}

Submission: December 06, 2017; Published: December 11, 2017

*Corresponding author: Ana Murta, Bachelor of Audiology, Coimbra Health School, Master Student of Biomedical Sciences, University Beira Interior, Professor of Audiology at Speech Therapy, School of Health at Setubal's Polytechnic, Portugal, Email: audiologistaanamurta@gmail.com

\section{Introduction}

Hearing loss affects the person with hearing loss and all of their surroundings, especially their communication partners. My contribution to the validation of the scale of auditory rehabilitation Goal Sharing for Partners Strategy (GPS) for European Portuguese aimed to increase the tools for evaluation and monitoring of hearing loss and its effects on the quality of life of one's own and those around him, but also to emphasize the importance of the companion in the whole Auditory Rehabilitation process.

\section{Hearing, hearing loss and handicap}

The human being, as a sociable being, uses language and speech to express himself and interact with society. Hearing is the sense of the human being whereby all communication with the environment is primarily involved, but also the sense organ that allows us to react to mechanical pressures and to defend from the surrounding environment. The importance of hearing when we are closed or sleeping is perceptible, we can perceive the danger even when other organs are «asleep». Hearing deprivation is always lived with great anxiety, it is essential an accurate diagnosis so that the therapeutic plan is put into practice in a short time without creating exclusion of the individual from family, social and / or professional life. The identification, measurement and classification of hearing loss are fundamental to formulate a diagnostic hypothesis and therapeutic plan.

The hearing loss can be classified according to the type in: transmission, sensorineural, mixed or central, depending on the affected structure of the auditory system. The hearing loss can be classified as: mild (21-40 dB), moderate (41-70 dB), severe (71$90 \mathrm{~dB})$, deep $(91-119 \mathrm{~dB})$ and cofose (> $120 \mathrm{~dB})$. The auditory handicap is the result of hearing impairment that limits or prevents the individual from performing his or her normal day-to-day tasks and still compromises their relationship with family, society and work. That is, we can consider that the handicap is the social expression of hearing disability in cultural, social, economic and environmental terms. The consequences are manifested also biologically, psychologically and socially, since the whole and the individual's surroundings undergo changes.

\section{Hearing Rehabilitation}

The main goal of health professionals is to minimize the consequences of hearing loss and to improve the quality of life of the individual and those who are closest to him. Auditory Rehabilitation should be used as a last resort, that is, after a good diagnosis and impossibility of resolution by medical-surgical methods. It is necessary to keep in mind that Hearing Rehabilitation does not cure, it acts only as a correction when using the device, and hearing loss is permanent. Hearing aids are considered a key part of the auditory rehabilitation process, since they are non-invasive and most of the results are satisfactory for the vast majority of hearing loss. It is extremely important that the equipment chosen is according to the type and degree of hearing loss, as well as all physical, acoustic and otological limitations. In addition to hearing aids, implants are also a resource for auditory rehabilitation, and in this case, they already require surgery and are therefore invasive methods that require a more exhaustive protocol to guarantee the success of the intervention.

In both situations it is extremely important to perceive the individual's motivation regarding the entire rehabilitation process. The chaperone at this stage is a great support for the whole process which tends to be somewhat time-consuming. It is important that the companion keep the individual motivated, who perceives the motivations and that works together to overcome or circumvent the limitations of the process. As previously mentioned, hearing loss affects everything that surrounds the individual, inviting the companion to be part of the whole process will decrease the affectation of their relationship in social life and day-to-day routines. Sharing responsibilities and information with someone other than the individual will create a positive impact for the family / relationship. 


\section{Goal Sharing for Partners Strategy (GPS)}

The GPS [1] allows us to perceive the effect of hearing loss on the partner, that is, what their perspective, experiences with other people, effects on the couple, communication and relationship and identify strategies to adopt with the partner. This tool makes it possible to understand the main difficulties for the individual and those who are related to him, enabling the health professional to assess the handicap more accurately and adapt strategies to the Auditory Rehabilitation process.

\section{Importance of accompanying person in auditory handicap information}

The companion of the individual with hearing loss proves to be a source of information about the whole relationship with the outside and auditory handicap. What is sometimes not felt by oneself, due to the slow progression of hearing loss, is easily noticed by the companion. This element in consultation of Auditory Rehabilitation can be important in the sensitization for the hearing loss of the own, but also to be sensitized and to better understand the limitations caused by the auditory handicap. The team formed by the health professionals involved, individual with hearing loss and partner will be the formula and the appropriate way to a successful Auditory Rehabilitation process [2-5].

\section{References}

1. BIAP (1996) The BIAP recommendations. BIAP International Bureau For Audiophonology. 26 de Outubro de.

2. Montano Joseph. Goal Sharing for Partners. IdaInstitute.

3. Nunes Rui Ribeiro (2003) Reabilitação auditiva e adaptação protética. José Luis Reis. Surdez diagnostico e reabilitação, Vol. II. Lisboa: SERVIER Portugal.

4. Scarinci, Nerina, Worrall, Linda e Hickson, Louise (2008) The effect of hearing impairment in older people on the spouse. International Journal of Audiology 3: 47.

5. Scarinci, Nerina, Worrall, Linda e Hickson, Louise (2009) The effect of hearing impairment in older people on the spouse: Development and phychometric testing of The Significant Other Scale for Hearing Disability (SOS-HEAR). International Journal of Audiology 10: 48.

\section{Your next submission with Juniper Publishers will reach you the below assets}

- Quality Editorial service

- Swift Peer Review

- Reprints availability

- E-prints Service

- Manuscript Podcast for convenient understanding

- Global attainment for your research

- Manuscript accessibility in different formats

( Pdf, E-pub, Full Text, Audio)

- Unceasing customer service

Track the below URL for one-step submission https://juniperpublishers.com/online-submission.php 